\title{
The Impact of E-Learning Apps On Child's Mental Agility
}

\author{
Pradeep Kumar Khiccha ${ }^{1}$, Shibani Soni ${ }^{2 *}$, Manisha Solanky ${ }^{3}$ \\ ${ }^{1}$ Lecturer, Dept. of Business Administration, Seth Mathuradas Binani Government College, Nathdwara, India \\ ${ }^{2,3}$ Research Scholar, Department of Business Administration, Mohanlal Sukhadiya University (University \\ College of Commerce and Management Studies), Udaipur, India \\ *Corresponding author: shibanisoni23@gmail.com
}

\begin{abstract}
Now-a-days students are more driven towards using mobile phones for every single purpose. Learning is a continuous process and the focus is now shifted towards E-learning. The objective of the study is to investigate the impact of educational apps on a child's mental agility. Every individual student has his/her unique way of thinking, understanding, and interpreting the concepts of a different subject. Some students find English as an interesting subject to some mathematics that may be out of his/her mind. To make their learning interesting and entertaining first the researchers thought to study the "impact of E-learning apps on child's mental agility". The study was conducted in the school in the Udaipur district where the sample size of 50 students was randomly selected of Grade I and Grade II. The mixed approach as adopted as a research method and type of research was Experimental Research. To evaluate the effectiveness of the educational apps pre-test and post was conducted using the traditional method of teaching and through e-learning mode. The result of the study claimed that there was a significant correlation between pre-test result and post-test results and from the study it can be concluded that there is a high impact of E-learning apps on a child's mental agility in the context of the development of knowledge, learning abilities, their creativity, easy understanding of complex topics and learning while playing through userfriendly interactive technology.
\end{abstract}

Keywords: E-Learning, E-Learning apps, Child mental agility, Smart class, Traditional teaching.

\section{Introduction}

Today, with the use of innovative technologies digital has come a long way along with virtual reality, artificial reality, and automation. Thus the digitalization is growing continuously to align with the customized learning needs and trends. With technological advances, organizations are focusing E-learning to boost engagement level, supporting teammate, and add the real value to money. E-learning is primarily teaching via the use of computers and in this wider sense, it has been described through many different terms such as computer-based training, online teaching, virtual teaching, web-based teaching, etc. Thus, the internet can be E-learning's greatest warhead. Elearning is the efficient use of various new multimedia technologies and tools along with the use of the internet to provide an interactive environment to learners by allowing them to access resources and services along with isolated interactions and collaboration. Besides, utility companies are seeking beneficial ways to provide optimum learning efficiency, workforce engagement, and customer satisfaction. With ever-evolving industries demands digitization, the traditional training model of the Utility industry is varying. Most of the enterprises face a wide spectrum of Service sectors demands that forced them to reshape their learning experiences with E-Learning.

The teaching process needs to be revolutionized along with changing technologies. The traditional and old paradigm of education requires the touch of new technologies to make the learning process fun instead of a task. Students face many problems academically as their concepts are not clear and find difficulty in the understanding subject due to old teaching methods. There is a need to provide students with additional resources like a computer, different technologies to make their effects. E-learning is primarily an integration of different hardware and software like modem, wireless, cable connection, computers, smartphones, handheld devices educational applications, and many more to effectively access the study material. The e-learning implementation can be improved by categorizing the challenges and pay attention according to the priority. There is a huge gap between the use of technology in schools and other educational institutions and allowing the learners to access them. The traditional method mainly relies on chalk, blackboard, and textbooks. Its emphasis on basic skills only while E-learning utilizing electronic technologies to access educational curriculum outside of a traditional classroom. ELearning apps are developed to target mobile and tablets platform. Applications are designed to rapidly accelerate to develop high-quality e-learning content such as (Youtube Kids, Dragon Box, Amazon Kindel, Edubuzz Kids, Kids All in One, Quick Maths), and Smart Class. Agility refers to mental quickness and sharpness. The central aspect of mental agility is fluidly springing around in your mind and body and attempting different thinking processes and testing out different solutions. E-learning opens the complete world of possibilities in the education field where students and teachers can share, engage, and convey unique ideas, theories, phenomena, and facts from remote locations. E-Learning has changed the dynamics of 
educational content and has opened new avenues to education in India.

\section{Purpose of Research}

The purpose of the research is to comprehend the notion of E-Learning Apps and to study the effectiveness of E-learning teaching methods on a child's mental agility. The researchers are also interested in knowing the attitude of teachers and students towards E-learning apps.

\section{Definition of Terms}

E-Learning: E-learning provides a flexible and hassle-free environment to the learners at affordable cost and many times free learning apps at convenient time and place. "E-learning is the generally the use of the web, electronic devices, and system to multiply the data and to provide access to information to learners. E-learning platform can be accessed through the integration of modem, wireless, or cable connection, computer, phone, or handheld device" (Governors State University, 2008)",

Traditional Teaching: Traditional or old teaching paradigm revolves around teaching methods that usually involve books reading, using the blackboard to elaborate any concept, and also utilization of charts, pictorial tools to provide depth insights. The traditional method emphasizes basic skills through the presentation of information.

E-Learning Apps - E-learning Apps are interactive students centered learning, edutainment (Education +Entertainment). Applications are designed to rapidly accelerate to develop highquality E-learning content such as (Youtube Kids, Dragon Box, Amazon Kindel, Edubuzz Kids, Kids All in One, Quick Maths), and Smart Class.

Agility: Refers to mental quickness and sharpness.

Child: The child in the study is defined as students falling between the age of 3 to 8 years and is monumental.

Mental Agility: Not all children are born equally thus their cognitive ability and mental capabilities vary with their age and the cognitive abilities can be developed through using effective teaching aids.

Grade I: In the study Grade I refer to students of class First.

Grade II: In the study Grade II refers to students of a class second.

\section{Review of Literature}

The literature reviewed by the researcher about Digital learning, E-leaning, smart classroom learning, and ICT technology in education is presented below:

\section{A. Summary of reviewed literature}

Jesus Valverde-Berrocoso, J., et. al (2020) [1], The Researcher presents a systematic literature review (SLR) to analyze the growth of educational research on e-learning and to identify the most relevant theories, the research topics, and the most researched models. The study is based on a literature review and the findings and results rest based on 249 literature reviews. The author found three main modalities of e-learning and they were students, teachers, and interactive curriculum. Massive Open Online Course was the most accessed modality in current period. Thus it can be concluded that E-learning studies and interactive learning environment oriented towards research is carried out in higher education and teaching learning emphasis on self-regulated learning. It deals especially with the progress of learning management system.

Roy, S. (2020) [2], this Empirical research study emphasis on two different studies concerning the Indian context to understand Indian e-learning readiness in 2013 and 2017 and to understand the recent trend. The finding indicates that there is a growth in internet usage in India. Consequently, the e-learning adaptation is also showing a positive trend over the years. K-12 sector showing rapid growth towards e-learning adaptation in the last 12 years (2007-2016). Also, prediction indicates that the growth rate will be continued in this sector. The government initiative, availability of cost-effective smartphones, and the data package is making the Indian e-learning market promising.

Lara, J. A., Aljawarneh, S., \& Pamplona, S. (2020) [3], the author explores the new trends in e-learning assessment through a systematic literature review. Different approaches in the study that are explored are block-chain techniques, gamification, the mining process, and many more. Thus it can be concluded that E-learning environment, design, analyses and interpretation contribute to new skills and knowledge and encourage advance implementation of software and hardware approaches with development of learning assessment.

Raju, A. D., Rithanya, S., Vegesna, G. M., \& Ivaturi, P. A. (2019) [4], the author emphasizes the scope of e-learning and focuses on different e-resources and web sites that are useful for learners and thus help in enhancing their knowledge. Through pie-charts researcher illustrates the different elearning components aesthetically. The author claimed that eresources are very useful and thus enhances the cognitive, skills, and abilities of learners.

P, D. R. (2019) [5], this study discusses the benefits of online banking and several distinct issues and challenges in the online banking sector. The outcome of the study shows that to tap into the power of digitization online banking marketers need to know these challenges so that they can efficiently direct them. However, banking rapidly transforming in the digital era. The author suggests that the banks should remain translucent and customers remain faithful. With the Technology awareness the individual likewise extent their lifestyle. More customers are adapting to E-learning platforms due to these there is an undoubted power that transform towards digital channels.

Baz, F. Ç. (2018) [6], The research paper emphasizes on the new trends that are trending in the world of e-learning. The concept of e-learning in the field of education leads to speedy progress. In this study, the concepts AI, Virtual and augmented reality, big data concept, blended learning modes, cloud computing, learning through games, m-learning, IoT, videos, 
blogs, etc. The author also attempts to provide insight on innovation in the field of e-learning by e-learners.

Kumar Basak, S., Wotto, M., \& Bélanger, P. (2018) [7], The research paper analyses the concept and terminologies of elearning, m-learning, and d-learning and attempts to evaluate the differences and similarities in these 3 learning modes. The findings claimed that d-learnings is the main head of online learning and e-learning and m-learning are the subsidiary of $\mathrm{d}$ learning. Many d-learning tools can fall under the category of both e-learning and m-learning. The author in the study claims that every learner needs to acquire basic knowledge of technologies and enhance the technical skills to get fit into the digital learning environment.

Hammad, J., Hariadi, M., Hery Purnomo, M., Jabari, N., \& Kurniawan, F. (2018) [8], this study attempt to present a brief overview of the e-learning concept, e-learning history, technology and future, Virtual Classes, adaptive e-learning, and case study. The author describes the development in the cyber learning is being so rapid in these systems. The features of adaptive learning are emphasized by comparing it with the other e-learning systems. It is concluded from this paper that adaptive learning has various aspects and will lead to a new era in learning. Adaptive learning enhances the learning ability by customizing the learning objects to the student needs and mapping it directly to the learning domain.

Panyajamorn, T., Suanmali, S., et al., (2018) [9], the research paper attempts to study and evaluate the effectiveness of online learning content and also compares with the effectiveness of offline teaching methods. The study emphasizes on few aspects of learning like motivation, satisfaction level of students, and experience that are inclined to the learning abilities. The finding suggests that specific patterns of the content were effective and interesting, and the satisfaction level of the student also widely affected learning abilities. The conclusion claimed that a blend of online and offline modes can help to solve the learning problems of students who are poor in their academics.

S. M. (2018) [10], This paper presents the positive and negative impact of gadgets on children. Research has been emphasizing on how gadgets impact on cognitive skills and motor skills of children. The author also suggests techniques through which parents can monitor their youngsters by limiting their time of gadget use. Suggestions have been given to help parents about their child's disclosure of gadgets. Boosting children to use it in the educational field can result in too drastic change.

Zanjani, N., Edwards, S., Nykvist, S., \& Geva, S. (2017) [11], this paper states the factors of important LMS design that affect user engagement such as E-Learning, notice process, and auto-correction features with E-Learning tools within the learning management system. Moreover, this study uniquely found that LMS design parameters affect the technology and privacy burden on the user's tendency to engage with LMS tools.

Nwigbo, S., \& B. K, M. (2016) [12], this paper demonstrates on ICT. It's a broad subject and the concepts are evolving. ICT helps ineffective interaction between teachers and students and thus allows them to identify and solve problems related to teaching and learning, helps in enhancing analytical and interpretations skills, save time and increase productivity, access to worldwide information, present content through the audio-visual method, provide collaborative learning sessions, and many more. ICT proves to be a boon for the teachers as well as for the students as it provides user interface technology, access to a wide range of information, and enhances communication skills.

Hendriks, D. (2016) [13], The research focuses on comparing the traditional learning methods with digital learning method and attempts to evaluate the outcome of the study based on the learning outcomes. The study adopts experimental design on 24 students picked from elementary school and the experiment continued for 3 weeks to evaluate the effectiveness of both methods. From the present study, the findings of the study emphasized the positive outcome of learning through digital learning methods as a student felt digital learning methods were interesting and interactive compared to traditional learning methods. A positive attitude is seen by teachers who were interviewed towards the use of tablet-based technology for education

Schalich, M. E. (2015) [14], the study explores and investigates the effectiveness and impact of small group instruction methods. This is a teacher action research project. Pre-test and post-test quantitative data are collected and analysed by the author. The sample size included 28 English learner students from grade- 1 to grade- 8 from one elementary school. Out of this 13 are male students and 15 are female students. The results claimed that teachers needs to understand individual background and set efforts to taught grammar, awareness of reading comprehensive strategies and encourage the students in group discussion to influence knowledge.

Yahaya, N. S., \& Salam, S. N. (2014) [15], this paper primarily focuses on a mobile app developed and specially designed for a child's cognitive age. The app's name is Belajar Bersama Dino. Here cognitive stage students are targeted for research purposes. The results of the study claimed that the developed mobile app proves to be effective in the hands of kids and enables kids to learn while playing the alphabets and numbers and basic concepts of kindergarten. Thus e-learning mode is one of the effective and interactive ways to engage and motivate children in their learning process.

Agarwal, H., \& Pandey, G. N. (2013) [16], this article explores the period when the concept of e-learning was introduced. This author also discusses its benefits, basic principles, and compares it with traditional education and Elearning. The author highlights some light on the result of using e-learning from three different viewpoints. The findings conclude that E-learning has various advantages over the traditional techniques of learning.

Lopuch, M. (2013) [17], this researcher aims to highlight the 
effects of educational apps on learners' engagement and achievement. The sample contains data with pre-test and posttests in reading. Findings established that iPad-based educational content has large effects on student achievement, and these effects are dissimilar to cost.

Jena, P. C. (2013) [18], this study focus on the effect of Smart classroom vs traditional method of teaching. The research method is an experimental one where pre-test and post-test have been conducted from a sample size of 60 students who were randomly selected and the statistical technique t-test was applied. The student's achievement tested through the smart classroom was better than the students who were taught in the traditional method. Therefore, this study concludes that the smart classroom has a significant difference over the traditional method.

Abaas, M. A. (2014) [19], the study adds literature to the discipline of E-learning and the paper emphasizes the development of a mobile apps for children to enhance and develop their cognitive skills in the pre-school. With the use of the proposed model, the existing instructional and content delivering teaching can be replaced effective, interactive and user interface mobile app. The results show that this realitybased approach delivers ease to both software development activities and knowledge modeling.

Sunhaloo, M. S., Narsoo, J., \& Gopaul, A. (2009) [20], this paper provides depth insights on the effectiveness of e-learning tools and focuses on their interactive features that have been developed for kids in Mauritius aged from eight to eleven years old. The author suggests developing software to promote selflearning and develop information and communication skills among the youngsters in Mauritius. The results of the study claimed that the e-learning tools for kids provide and user interface and interactive interface to users and also helps in enhancing the skill and knowledge. The interactive and supporting study material helps kids in improving their overall efficiency.

\section{Research Gap}

Prior studies revealed that E-learning, ICTs, and smart classroom are effective ways to teach students but the researcher here had to find out the impact of E-learning apps on a child's mental development. So this research study fills the entire research gap.

\section{Objective of Study}

The proposed research work has been undertaken to meet the following objective:

1. To familiarize students with E-Learning Apps.

2. To study the effectiveness of traditional teaching and E-learning methods on a child's mental agility.

\section{Hypothesis}

Ho- There is no significant difference between Traditional teaching and E-Learning Apps Teaching on a child's mental agility.

\section{Research Methodology}

\section{A. Research Approach - Mixed Approach}

Research Design: The study investigates and evaluates the students' performance based on pre-test and post-test through Mixed Approach. The study was conducted at M.D Academy where students from Grade I and Grade II were randomly selected. The students were given an immediate Pre-test and later on, the students were divided into two equal groups namely Group I and Group II

Sample size:

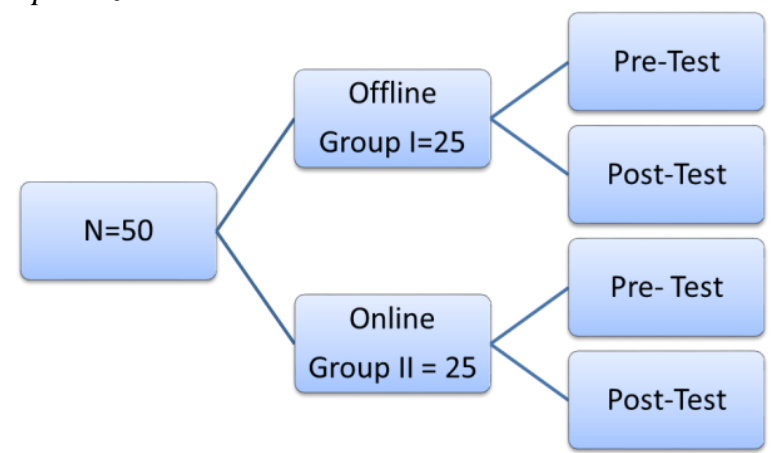

Data were collected from one elementary school, Students were 50 students were randomly selected from a population size of 200 students of Grade I and Grade II.

Data Gathering Procedure:

The participants for this study were given an instant test on subjects like maths, G.K which were already part of their academic curriculum, the 50 students were divided into 2 equal groups. Offline teaching sessions of 2 hours was conducted for Group 1 and Group 2 Students were taught through E-Learning Apps for 2 Hours. The sessions included selected topics from subject Mathematics and General knowledge.

Questionnaire: The questionnaire consists of 10 questions. Questions included the topic from Mathematics and General knowledge. Question types include matching the right answer, recognition of birds, animals, and famous personality, and fill in the blanks.

\section{B. Data Analysis}

\section{Interpretation:}

The table 1, shows data of Group I which consists of 25 students of Grade I and II. The student's pre-test and post-test results have been drawn through a marking system. Question papers weightage was of 50 marks and accordingly marks were awarded to students, the average marks of pre-test of 25 students were 27.44. Later on, students were given two-hour traditional teaching sessions and a post-test was conducted respectively and the average marks of the post-test were 30.68 . The result did not show a much impactful increase or decrease 
Table 1

Traditional method

\begin{tabular}{|l|l|l|l|l|l|}
\hline \multicolumn{5}{|c|}{ Traditional Method } \\
\hline Respondents & pre-test & \% & post-test & \% & Improvement in mental agility \\
\hline 1 & 23 & $46 \%$ & 26 & $52 \%$ & 3 \\
\hline 2 & 43 & $86 \%$ & 46 & $92 \%$ & 3 \\
\hline 3 & 16 & $32 \%$ & 19 & $38 \%$ & 3 \\
\hline 4 & 35 & $70 \%$ & 41 & $82 \%$ & 6 \\
\hline 5 & 23 & $46 \%$ & 27 & $54 \%$ & 4 \\
\hline 6 & 22 & $44 \%$ & 25 & $50 \%$ & 3 \\
\hline 7 & 29 & $58 \%$ & 30 & $60 \%$ & 1 \\
\hline 8 & 32 & $64 \%$ & 32 & $64 \%$ & 0 \\
\hline 9 & 37 & $74 \%$ & 39 & $78 \%$ & 2 \\
\hline 10 & 42 & $84 \%$ & 45 & $90 \%$ & 3 \\
\hline 11 & 26 & $52 \%$ & 29 & $58 \%$ & 3 \\
\hline 12 & 23 & $46 \%$ & 31 & $62 \%$ & 8 \\
\hline 13 & 32 & $64 \%$ & 37 & $74 \%$ & 5 \\
\hline 14 & 41 & $82 \%$ & 49 & $98 \%$ & 8 \\
\hline 15 & 28 & $56 \%$ & 25 & $50 \%$ & -3 \\
\hline 16 & 40 & $80 \%$ & 45 & $90 \%$ & 5 \\
\hline 17 & 25 & $50 \%$ & 26 & $52 \%$ & 1 \\
\hline 18 & 17 & $34 \%$ & 18 & $36 \%$ & 1 \\
\hline 19 & 36 & $72 \%$ & 39 & $78 \%$ & 3 \\
\hline 20 & 17 & $34 \%$ & 18 & $36 \%$ & 1 \\
\hline 21 & 12 & $24 \%$ & 17 & $34 \%$ & 5 \\
\hline 22 & 24 & $48 \%$ & 28 & $56 \%$ & 4 \\
\hline 23 & 18 & $36 \%$ & 22 & $44 \%$ & 4 \\
\hline 24 & 19 & $38 \%$ & 24 & $48 \%$ & 5 \\
\hline 25 & 26 & $52 \%$ & 29 & $58 \%$ & 3 \\
\hline Average marks & $\mathbf{2 7 . 4 4}$ & & $\mathbf{3 0 . 6 8}$ & & \\
\hline & & & & \\
\hline
\end{tabular}

Table 2

E-learning Apps

\begin{tabular}{|c|c|c|c|c|c|}
\hline \multicolumn{6}{|c|}{ E-learning Apps } \\
\hline Respondents & Pretest & $\%$ & Post-test & $\%$ & Improvement in mental agility \\
\hline 1 & 28 & $56 \%$ & 49 & $98 \%$ & 21 \\
\hline 2 & 30 & $60 \%$ & 44 & $88 \%$ & 14 \\
\hline 3 & 35 & $70 \%$ & 48 & $96 \%$ & 13 \\
\hline 4 & 25 & $50 \%$ & 42 & $84 \%$ & 17 \\
\hline 5 & 27 & $54 \%$ & 43 & $86 \%$ & 16 \\
\hline 6 & 24 & $48 \%$ & 40 & $80 \%$ & 16 \\
\hline 7 & 35 & $70 \%$ & 46 & $92 \%$ & 11 \\
\hline 8 & 32 & $64 \%$ & 43 & $86 \%$ & 11 \\
\hline 9 & 31 & $62 \%$ & 43 & $86 \%$ & 12 \\
\hline 10 & 40 & $80 \%$ & 41 & $82 \%$ & 1 \\
\hline 11 & 21 & $42 \%$ & 41 & $82 \%$ & 20 \\
\hline 12 & 22 & $44 \%$ & 43 & $86 \%$ & 21 \\
\hline 13 & 35 & $70 \%$ & 42 & $84 \%$ & 7 \\
\hline 14 & 36 & $72 \%$ & 45 & $90 \%$ & 9 \\
\hline 15 & 30 & $60 \%$ & 45 & $90 \%$ & 15 \\
\hline 16 & 38 & $76 \%$ & 47 & $94 \%$ & 9 \\
\hline 17 & 33 & $66 \%$ & 49 & $98 \%$ & 16 \\
\hline 18 & 16 & $32 \%$ & 38 & $76 \%$ & 22 \\
\hline 19 & 28 & $56 \%$ & 45 & $90 \%$ & 17 \\
\hline 20 & 27 & $54 \%$ & 48 & $96 \%$ & 21 \\
\hline 21 & 22 & $44 \%$ & 42 & $84 \%$ & 20 \\
\hline 22 & 26 & $52 \%$ & 38 & $76 \%$ & 12 \\
\hline 23 & 20 & $40 \%$ & 30 & $60 \%$ & 10 \\
\hline 24 & 19 & $38 \%$ & 39 & $78 \%$ & 20 \\
\hline 25 & 26 & $52 \%$ & 39 & $78 \%$ & 13 \\
\hline Average marks & 28.24 & & 442.8 & & \\
\hline
\end{tabular}

in the marks as compared to the pre-test. May be due to the same and familiar teaching methods.

Interpretation:

The table 2, shows the results of Group II students of sample size 25. These students were also given an instant Pre-test and the results were drawn through a marking system. Group II students went under a two-hour E-learning teaching session. In this session, students were taught through Educational apps like Edubuzz, all in one app, etc. And later on, the post-test was conducted as per our requirement. The average marks of the 
students in the pre-test were 28.24 and the average marks of the students in the Post-test were 42.8. The Group II student's results were better than the Pre-testing terms of their average marks. When students were taught through the educational app they were very much attentive and were very much interested and curious in learning the concepts through playing. And due to this post-test showed an upward graph of their marks.

\begin{tabular}{|l|l|l|}
\multicolumn{3}{|c|}{ Table 3 } \\
\hline \multicolumn{3}{|c|}{ Correlation } \\
\hline Group I and Group II & & \\
\hline pre-test & 0.64073 & positively correlated \\
\hline post-test & 0.151647 & negatively correlated \\
\hline
\end{tabular}

\section{Interpretation:}

The statistical tool was applied to find out the correlation of Group I and Group II results.

The pre-test correlation results of Group I and Group Two were highly correlated. Here we assume that the students who were randomly selected had a similar state of mental agility due to the familiarity of the topics and subjects which were asked in the questionnaire.

The post-test correlation results of Group I and Group II were negatively correlated. The post-test results were negatively correlated due to the teaching Methods i.e., traditional method teaching vs E-learning apps. The results of the pre-test of Group I and Group II in the context of the average marks did not show many differences (i.e. Group I $=27.44$ and Group II $=28.24$ )

But the results of the Post-test of both the Groups had major differences in the context of the average marks (i.e., Group I $=30.68$ and Group II $=42.8$ ). Here the major difference is seen in the post-test results of Both groups, as the group, I was taught in the traditional method and the group II were taught through an e-learning app. Student learning through e-learning apps was very much attentive and was also very much attracted to the audio-video effects of the app whereas the traditional method did not support such effectiveness.

\section{Findings}

1. Knowledge-based results: The overall results of Group I and Group II in context to their knowledge showed that Group II students gave more right answers in the post-test as compared to the Group I. Group I students' knowledge level did not differ more as compared to the pre-test and post-test, it was due to the same environment and same method of teaching through textbooks, chalk, and board. There was one student who did not show any difference in the pre-test and Post-test and his/her result was the same. And we also found one student result in negative as compared to its pretest and post-test this showed that many times students don't turn up to the traditional teaching effectiveness and maybe he was physically present and mentally absent in the twohour traditional teaching session. Group II students showed more interest in learning through e-learning app as they were user friendly and were very attractive with advance features, visuals which easily attracted students' attention.

2. Learning-based results: In the sessions, we kept interacting with students to know whether they understood the concept or not. All the students responded positively towards both the teaching methods. Group, I students responded positively towards learning outcomes but due to their same method of teaching did not create and enthusiasm and imitativeness to learn more which was seen in Group II students. Group II students responded that they learned effectively through E-learning apps in terms of pictures, visuals, and education through entertainment. Retention power was strong among the students while taking a posttest. 3 students did not take much interest in the session and after asking them we found out that their parents did not have smartphones but they enjoyed the session. Interactive technology can positively support our education system, children, parents, and teachers.

3. Teachers' way of thinking: we interacted with few primary teachers to know what they think about e-learning apps. Most of the teachers preferred the implication of Interactive technology and Apps for the student's purposes. E-learning apps can make teacher work easy to make the student understand the concept and improve students learning capabilities through edutainment (education + entertainment). Teachers had positive attitudes towards Elearning methods.

\section{Limitation}

One of the major limitations was the time, we had to complete our pre and post-test within the time specified by the school authorities. And students also had the pressure of completing their class works on time.

The understanding power and reading capability of grade I and Grade II students was low due to which we had to readout question loudly and we also had to give relaxation in terms of spelling of few difficult words. For students, we also recorded their answers orally.

Few students complained that their parents did not have smartphones which were a major limitation due to which we could not convey our purpose to them effectively.

\section{Further Scope of Research}

Due to some difficulties in research, some aspects of this study remain open for researchers

First: Our sample was from Grade I and Grade II researcher can take higher grade students for further study on the effectiveness of e-Learning apps.

Second: The sample size was small; the researchers can go for larger sample size for best and effective results,

Third: Our study focused on the age group for 3 to 8 years. A researcher can choose different age groups for more accurate results.

Fourth: The study was conducted in the year 2018 and the results claimed that e-learning is an effective way of teaching 
student's comparative to traditional methods thus the impact and other effectiveness of E-learning can be better explored and investigated during the lockdown of schools due to the pandemic.

\section{Implications of the Study}

To the teachers: Teachers can encourage students to learn through suggested e-learning app

Which they feel can fulfill a student's purpose and their purpose too. Learn through playing is an emerging phenomenon that can be adopted by teachers to improve and enhance the learning power and knowledge of the students. Teachers need to enhance their knowledge through various e-learning tools and techniques to make learning fun and effective. Teachers can use these tools to spark student curiosity and explore presentation literacy skills. Effective and interactive userfriendly content needs to be made by teachers to provide an effective learning environment for the learners. Effective Learning Management systems need to be developed to enhance the knowledge of students.

To the students: Students of every grade can take the help of different E-learning apps that are available on various online stores like Google play store. Many apps are suitable for different classes like for primary classes apps like Edubuzz, all in one, kids G.k., Nursery to 3rd standard E-learning apps, for 10 and 12th student's apps like Khan Academy, BYJUs, My CBSE guide, OYEEXAMS, and the list is endless can be very useful. E-learning apps prove easier to learn things and remember them. Individuals can harness the power of everyday technology to bring real-world learning.

To the parents: Now-a-days children are too much addicted to smartphones and so our children are also one among them. Parents can download a few Educational apps which they think can be beneficial to the child or any particular subject related to which the child lack interest. These apps will help them learn through the easy interface, games, mind puzzles, quizzes, and many apps that have features of tracking a child's progress. Let the child utilize their leisure time effectively through edutainment.

To aspiring entrepreneurs: if anyone of you is thinking of becoming an entrepreneur then the idea of making e-learning apps with great user interface and with advanced features can be a great one as we are moving towards interactive technology and in near future, we may go paperless to save Earth. Effective and interactive content for students can be developed through new and innovative ways by aspiring entrepreneurs.

\section{Conclusion}

Regardless to many limitations, this study showed that students educational app and other E-learning methods are having and will have a great impact on child's mental agility in terms of knowledge, IQ level, creativity, learning capabilities, logical reasoning, and retention power which overall develops a student's mental agility. Hence there is a great impact of E- learning apps on child mental agility. The findings of the study also claimed that many teachers were between the age of 39- 48 so they did not appreciate technology up-gradation and few teachers liked the idea of teaching students through apps as apps were user friendly and the education was interactive and interesting and engaged students in effective learning mode. Thus there is a need to make attempts through E-learning to make learning more fun, interactive, and interesting. The future of academic may call upon the Artificial Intelligence implanted E-learnings. Virtual learning will be the need of the hour and for all these teachers, parents and students need to be technosavvy. Education is a mindful attempt to encourage effective learning and developing skills and knowledge. To accomplish this, different pedagogies need to be adopted by teachers and schools. With the advent of novel information and communication technologies and the internet, the teaching and learning process is simplified and enlarged to the birth of Elearning.

\section{References}

[1] Valverde-Berrocoso, J., del Carmen Garrido-Arroyo, M., Burgos-Videla, C., \& Morales-Cevallos, M. B. (2020). Trends in educational research about e-Learning: A systematic literature review (2009-2018). Sustainability (Switzerland), 12(12).

[2] Roy, S. (2020). e-learning Scope and Trend in India e-learning Scope and Trend in India.

[3] Lara, J. A., Aljawarneh, S., \& Pamplona, S. (2020). Special issue on the current trends in E-learning Assessment. Journal of Computing in Higher Education, 32(1), 1-8.

[4] Raju, A. D., Rithanya, S., Vegesna, G. M., \& Ivaturi, P. A. (2019). The Scope of e-Learning - A Research. International Journal of Engineering and Advanced Technology, 9(2), Volume-9 Issue-2, December 2019.

[5] P, D. R. (2019). Digital Banking Challenges and Opportunities in India. EPRA International Journal of Economic and Business Review, December, 20-23.

[6] Baz, F. Ç. (2018). New Trends in e-Learning. Trends in E-Learning, 116.

[7] Kumar Basak, S., Wotto, M., \&Bélanger, P. (2018). E-learning, Mlearning, and D-learning: Conceptual definition and comparative analysis. E-Learning and Digital Media, 15(4), 191-216.

[8] Hammad, J., Hariadi, M., HeryPurnomo, M., Jabari, N., \&Kurniawan, F. (2018). E-learning and Adaptive E-learning Review. IJCSNS International Journal of Computer Science and Network Security, 18(2), 48.

[9] Panyajamorn, T., Suanmali, S., Kohda, Y., Chongphaisal, P., \&Supnithi, T. (2018). Effectiveness of E-Learning Design in Thai Public Schools. Malaysian Journal of Learning and Instruction, 15(1), 1-34.

[10] S, M. (2018). The Impact of using Gadgets on Children. (2018). Journal of Depression and Anxiety.

[11] Zanjani, N., Edwards, S., Nykvist, S., \& Geva, S. (2017). The Important Elements of LMS Design that affect user engagement with E-Learning tools within LMS in the Higher Education Sector. Australasian Journal of Educational Technology, 33(1).

[12] Nwigbo, S., \& B.K, M. (2016). Impact of ICT on the Teaching and Learning Process. IOSR Journal of Mobile Computing \& Application,3(2), 01-07.

[13] Hendriks, D. (2016). Comparing traditional and digital learning methods to improve the learning outcomes of young children.

[14] Schalich, M. E. (2015). Analysis of Pre Test and Post Test Performance of Students in a Learning Center Model at the Elementary School Level.

[15] Yahaya, N. S., \& Salam, S. N. (2014). Mobile Learning Application for Children: Belajar Bersama Dino. Procedia - Social and Behavioral Sciences 1, 155, 398-404.

[16] Agarwal, H., \& Pandey, G. N. (2013). Impact of E-Learning in Education. International Journal of Science and Research (IJSR), 2(12). 
[17] Lopuch, M. (2013). The Effects of Educational Apps on Student Achievement and Engagement.

[18] Jena, P. C. (2013). Effect of Smart Classroom Learning Environment on Academic Achievement of Rural High Achievers and Low Achievers in Science. International Letters of Social and Humanistic Sciences, 3, 1-9.

[19] Abaas, M. A. (2014). Onto Cog: A Knowledge-Based Approach for Preschool Cognitive Skills Learning Application. International
Conference on Innovation, Management and Technology Research, Malaysia, 460-468.

[20] Sunhaloo, M. S., Narsoo, J., \& Gopaul, A. (2009). An Interactive ELearning Tool for Kids in Mauritius. Issues in Informing Science and Information Technology,

[21] https://en.wikipedia.org/wiki/Digital_learning

[22] https://flexiblelearning.auckland.ac.nz/learning_technologies_online/6/1/ html/course_files/1_2.html 